\title{
Mongolian Journal of Chemistry
}

The Institute of Chemistry \& Chemical Technology

\section{Characterization of ash pond ashes from $3^{\text {rd }}$ thermal power plant by SEM/EDX and XRD methods}

\author{
A. Minjigmaa ${ }^{1}$, Ts. Zolzaya ${ }^{1}$, E. Bayanjargal ${ }^{2}$, B. Davaabal ${ }^{1}$, J. Temuujin ${ }^{1}$ \\ ${ }^{1}$ Laboratory of Materials Science and Technology, Institute of Chemistry and Chemical Technology, MAS, \\ Peace ave., Ulaanbaatar 13330, Mongolia \\ ${ }^{2}$ Laboratory of Natural Science, Mongolian Academy of Sciences
}

ARTICLE INFO: Received 29 October 2013; revised 6 December 2013, accepted 10 December 2013

Abstract: Coal combustion by products from ash pond of $3^{\text {rd }}$ thermal power plant of Ulaanbaatar city have been collected in 2010 and 2013 years. The ash samples have been characterized by XRD, XRF and SEM-EDX methods in order to evaluate their chemical and mineralogical composition changes with disposed times. The mineralogical composition of ash varies with time though the chemical composition of the ashes were close each other. Possibly, inefficient operating condition of the TPS shows influence on the mineralogical composition.

Keywords: coal combustion by products, thermal power station, XRD, SEM/EDX, characterisation

\section{INTRODUCTION}

Approximately $10-30 \%$ of the original coal is noncombustible and remains as solid by-products after burning in the thermal power plants. Generally, the chemical, mineralogical composition and volume of the coal combustion by-products are determined by the content and composition of the inorganic constituent of the original coal and design and operation of the power station [1]. Coal combustion by-products (CCP) also can be divided into different types; namely bottom ash or boiler slag, fly ash and flue gas desulphurisation materials. Ahmaruzzaman has stated that the world's current annual production of coal ash is around 600 million tonnes of which fly ash are about 500 million tonnes [2]. But the latest references indicate that over 750 million tonnes of the ashes are produced worldwide while only $25 \%$ is being recycled $[3,4]$.

A schematic diagram for the different coal combustion products collected during power generation is shown in Fig. 1.

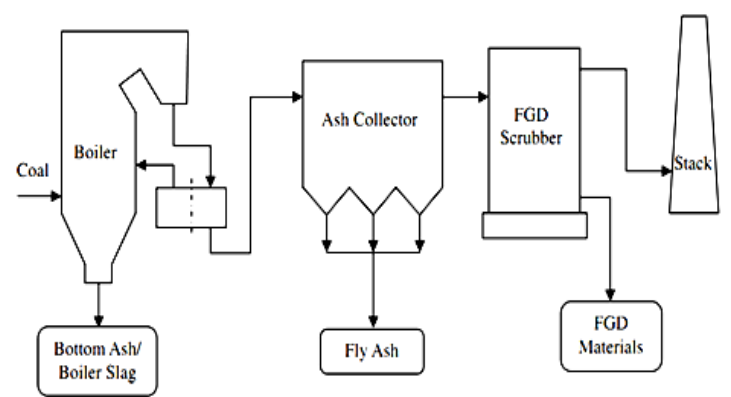

Fig. 1. Schematic diagram of coal combustion by productscollection.

* corresponding author: e-mail: a_minji@yahoo.com
The majority of coal firing residue from Mongolian power plants cannot be considered as fly ash.

At this time, only the TPS4 has an electrostatic separator to collect fly ash. Other thermal power stations are producing bottom ash or boiler slags. The two largest thermal power stations in Ulaanbaatar city are using a huge volume ash pond to keep the removed coal combustion by-products wet. However, due to a land shortage in Ulaanbaatar city, there is problem to build a new ash pond.

In the laboratory of Materials Science and Technology of Institute of Chemistry and Chemical Technology at presently performs research on beneficial utilization of the coal combustion by products from the Mongolian thermal power plants [5].

However, one of the main problems encountering in coal combustion by products utilization is nonuniformity of these by products in terms of chemical and mineralogical compositions with time of production. Because of such non-uniformity of the ash products, difficult to create a technological procedure applicable for the ashes collected in different years.

The aim of the present research is to characterize coal combustion by products by the analytical techniques and to elucidate differences of the ashes collected in different years.

\section{EXPERIMENTAL}

For the experiments were used ash pond ashes from the $3^{\text {rd }}$ Thermal power plants collected in 2010 and 2013 years.

The chemical composition of the ashes was determined by X-ray fluorescence (XRF). SEM/EDX (scanning electron microscopy equipped with the 
energy dispersive spectroscopy) was taken at S$3400 \mathrm{~N}$, Hitachi microscope. In order to determine the mineralogical composition of the ash products the XRD patterns were collected on Shimadzu MAXima_X XRD-7000 diffractometer using CuK $\alpha$ radiation.

\section{RESULTS AND DISCUSSION}

Chemical composition of the ashes collected in 2010 and 2013 is shown in Table 1.

Table 1. Chemical composition of the ashes collected from ash pond of $3^{\text {rd }}$ thermal power station

\begin{tabular}{ccccccccccccccc}
\hline Ashes & $\mathrm{SiO}_{2}$ & $\mathrm{Al}_{2} \mathrm{O}_{3}$ & $\mathrm{Fe}_{2} \mathrm{O}_{3}$ & $\mathrm{CaO}$ & $\mathrm{MgO}$ & $\mathrm{MnO}$ & $\mathrm{SO}_{3}$ & $\mathrm{~K}_{2} \mathrm{O}$ & $\mathrm{SrO}$ & $\mathrm{TiO}_{2}$ & $\mathrm{Na}_{2} \mathrm{O}$ & $\mathrm{P}_{2} \mathrm{O}_{5}$ & $\mathrm{~V}_{2} \mathrm{O}_{5}$ & $\mathrm{LOI}$ \\
\hline $\begin{array}{c}3 \text { rd TPS } \\
(2010)\end{array}$ & 52.3 & 15.45 & 10.1 & 16.55 & 1.94 & 0.112 & 1.36 & 1.52 & 0.24 & 0.299 & - & - & - & 11.01 \\
$\begin{array}{l}3^{\text {rd }} \text { TPS } \\
(2013)\end{array}$ & 53.24 & 14.57 & 8.9 & 15.52 & 1.25 & 0.227 & 0.46 & 1.25 & - & 0.67 & 0.23 & 0.08 & 0.03 & 13.72 \\
\hline
\end{tabular}

Table 1 indicates that there are not many changes in terms of chemical composition. The highest changes were observed for the calcium and iron contents

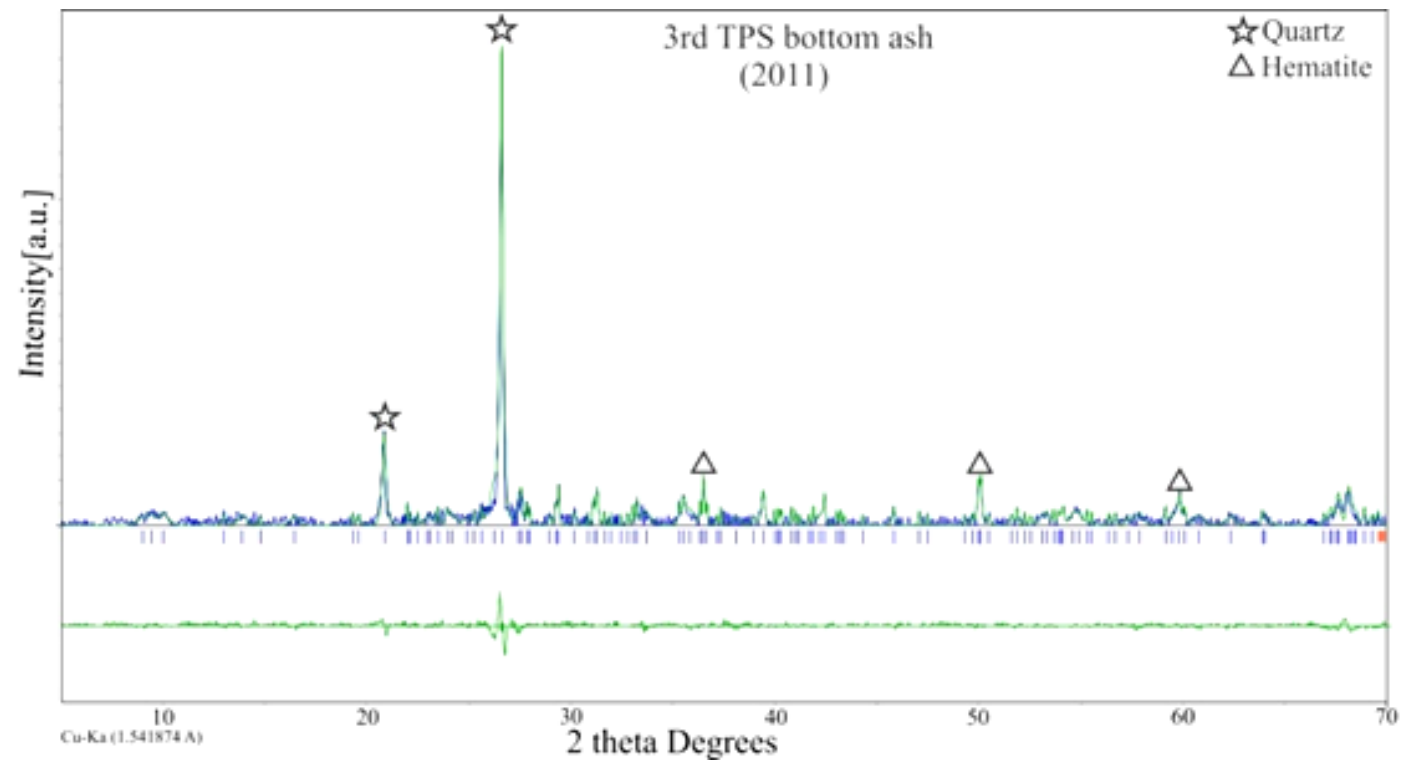

Fig. 2. XRD pattern of the ash collected in 2010.

XRD pattern indicates the quartz and hematite were main crystalline components. A detailed investigation

of the XRD pattern also revealed presence of negligible amount of akkermanite and calcite.
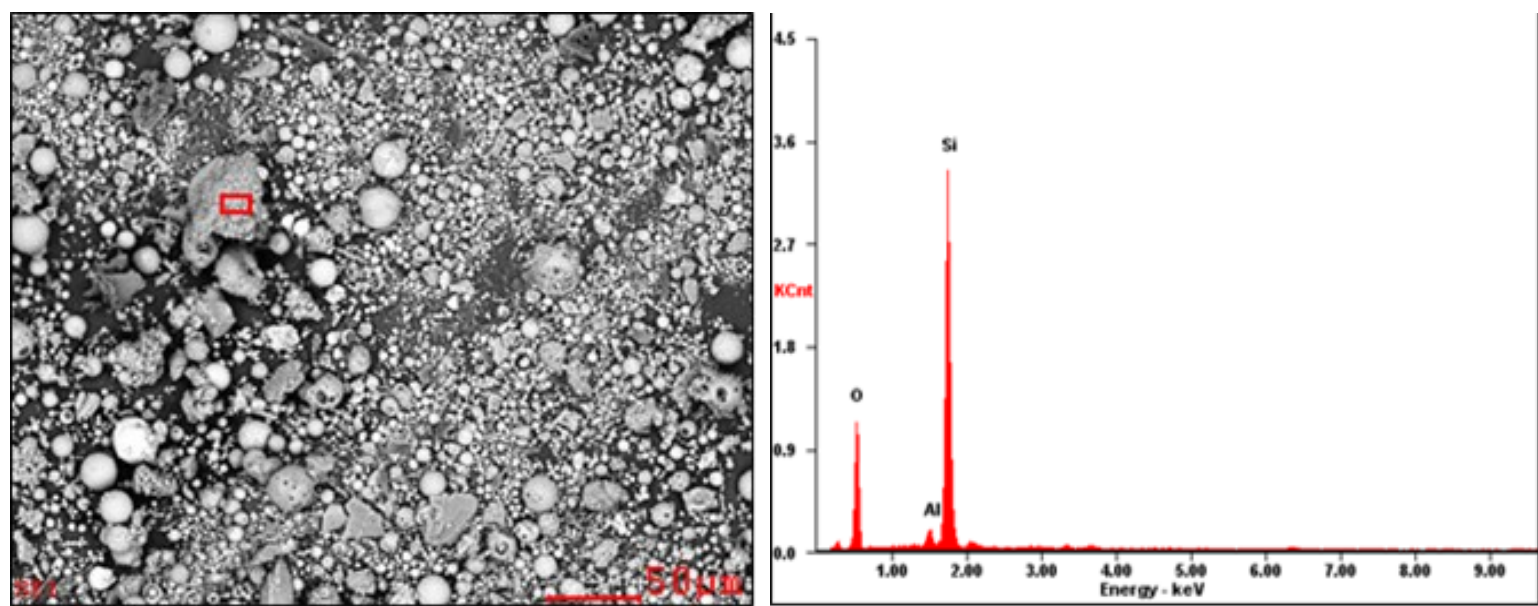
Mongolian Journal of Chemistry 14 (40), 2013, p2-3
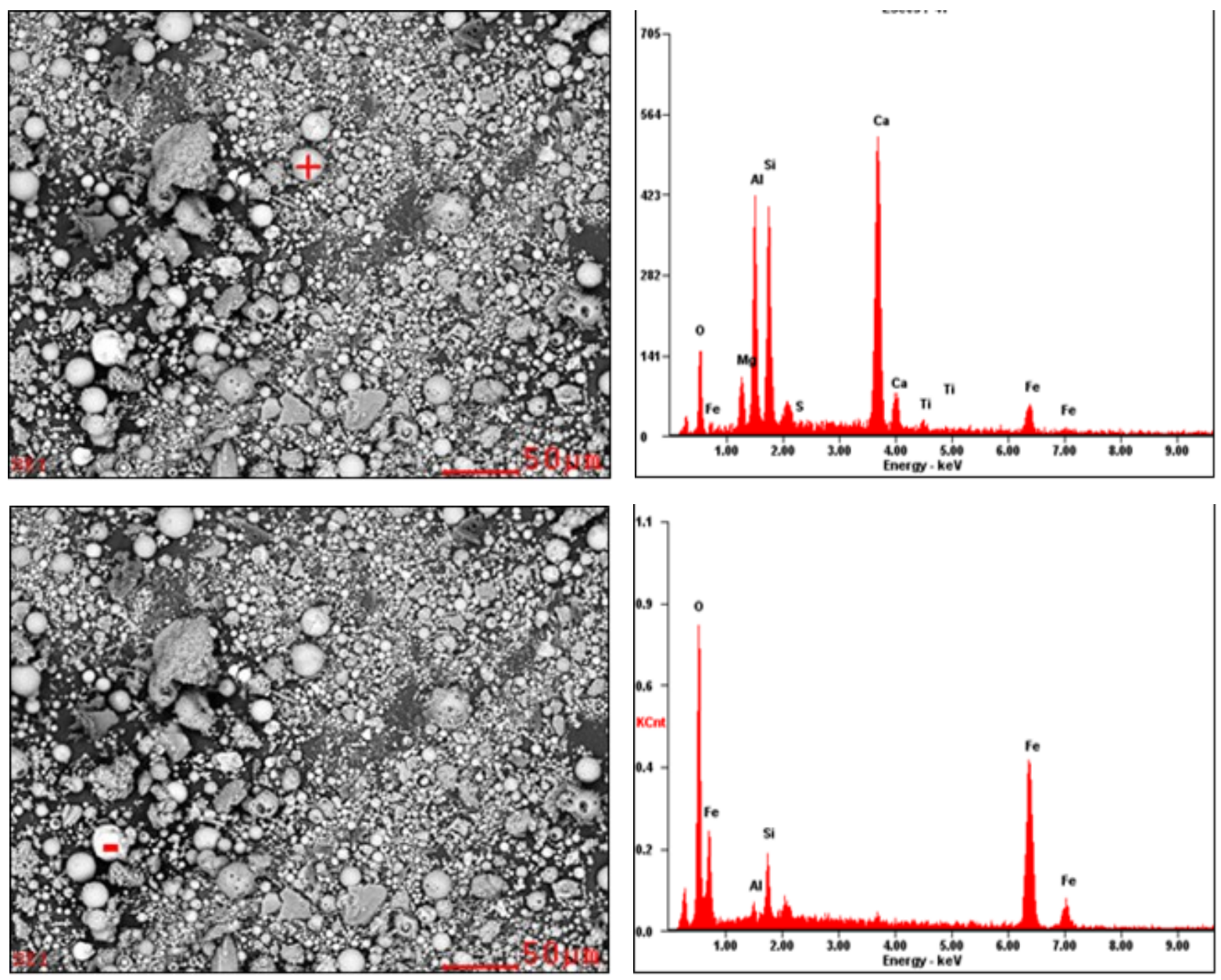

Fig. 3. SEM images and EDX spectra of ashes collected in 2010.

EDX spectra is well agrees with the chemical and iron containing compounds. Fig. 4 shows XRD mineralogical analysis data and revealed presence of pattern of the ash collected in 2013. the quartz, amorphous calcium aluminosilicate and

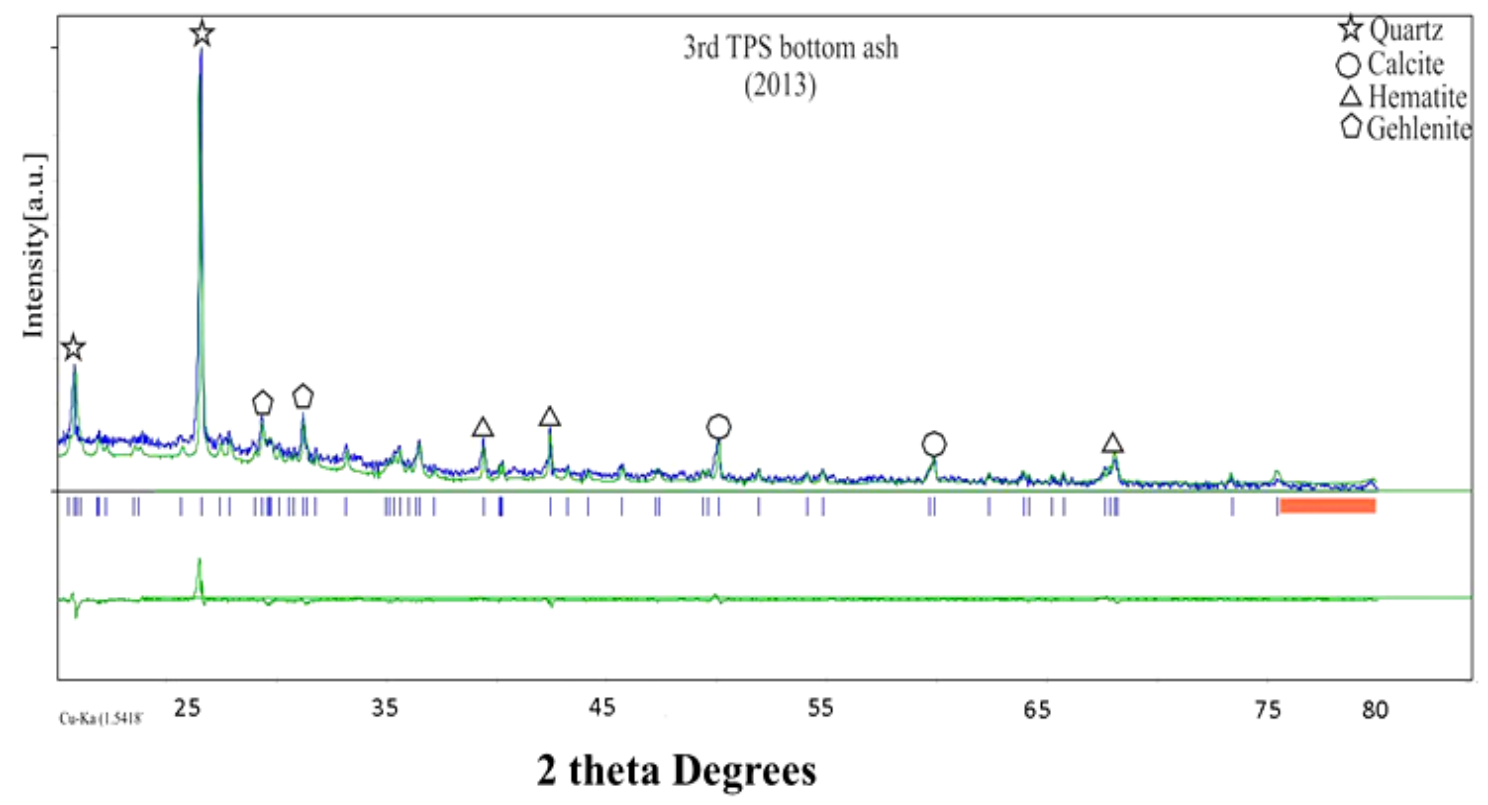

Fig. 4. XRD pattern of the ash collected in 2013. 
Generally both XRD of Fig. 2 and Fig. 4 resemble each other. However, peaks assigned to calcite $\left(\mathrm{CaCO}_{3}\right)$ and Gehlentite $\left(\mathrm{Ca}_{2} \mathrm{Al}\left[\mathrm{AlSiO}_{7}\right]\right)$ were more clear in the sample collected in 2013. It indicates difference of
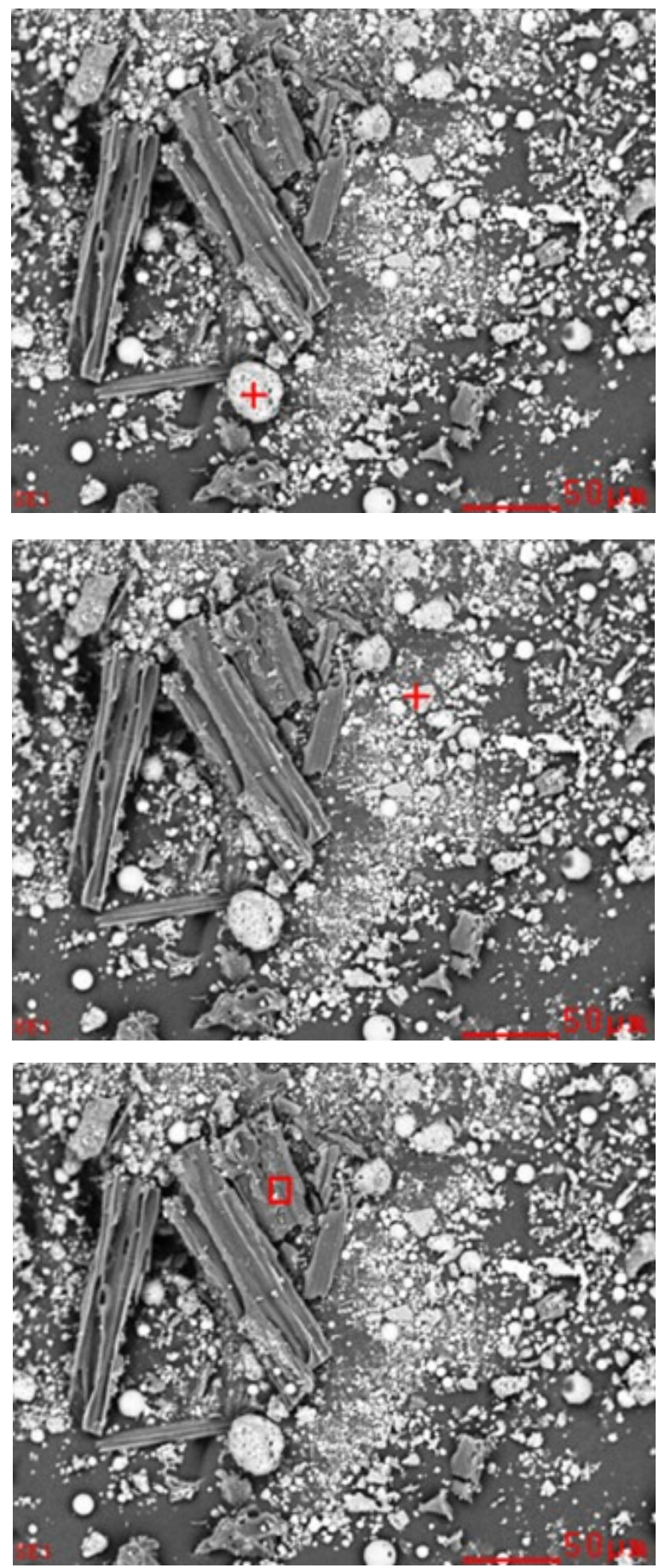

mineralogical composition though their chemical compositions were closer.

Fig. 5 shows SEM/EDX of the samples collected in 2013.
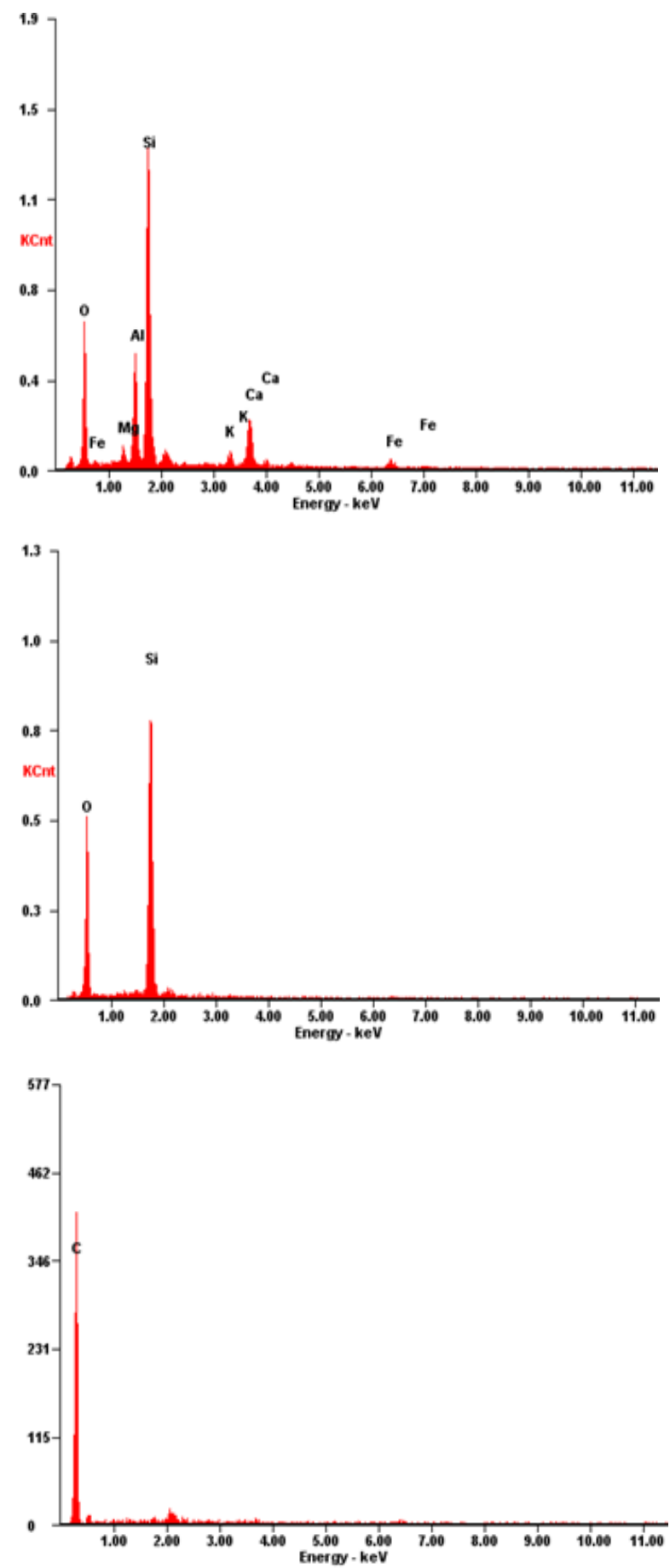

Fig. 5. SEM images and EDX spectra of ashes collected in 2013

The EDX spectra suggest that $\mathrm{Ca}$ bonds with $\mathrm{Si}, \mathrm{Al}$ and $\mathrm{Mg}$ and strongly support the XRD results. Although both ashes show similar features in the EDX spectra, unburnt carbon was observed in the ash collected in 2013. Also XRD pattern of this ash shows presence of calcite. Generally calcite decomposes around 900$1000^{\circ} \mathrm{C}$ which is lower than usual coal burning temperature of thermal power stations. The coal firing temperature of the most of coal fired thermal power stations is over $1000^{\circ} \mathrm{C}$. However, presence of the calcite in both samples indicates that the coal burning temperature of the $3^{\text {rd }}$ thermal power station is lower than usual coal firing temperature. Moreover, ash collected in 2013 also contains higher amount 
of calcite and unburnt carbon. It is most likely related with an operating condition of this plant in 2013. The coal burning temperature around 2012 - 2013 was likely to be lower than those 2010 - 2011 years.

Generally unburnt carbon is undesirable for utilization of ash products in building and construction materials production. Using of ashes containing high unburnt carbon for concrete production caused increase of water content of reaction mixture which is undesirable. Therefore, separating of unburnt carbon from those ashes with high carbon content is necessary step prior their utilization.

$3^{\text {rd }}$ thermal power plant uses Baganuur coal and mineralogical composition changes of the coal in 2010 - 2011 and 2012 - 2013 years likely to be not much. However, possibly caused by operating parameters, ash pond ashes collected in 2013 contains higher amount of calcite and unburnt carbon.

\section{CONCLUSIONS}

There is not much difference in terms of chemical composition of ashes collected in 2010 and 2013 years from the ash pond of the $3^{\text {rd }}$ thermal power station.
Mineralogical composition of the ashes from coal fired thermal power plants depend on operating conditions of plant. Ash collected from the $3^{\text {rd }}$ thermal power plant in 2013 contains higher amount of unburnt carbon and calcite than that ash collected in 2010.

\section{ACKNOWLEDGEMENT}

The present research was supported by the Science and Technological Foundation of Mongolia.

\section{REFERENCES}

1. Jha V., Matsuda M., Miyake M. (2008) Journal of the ceramic society of Japan, 116, 165-175

2. Ahmaruzzaman M. (2010) Progress in Energy and Combustion Science, 36, 327-363.

3. Blissett R.S., Rowson N.A. (2012), Fuel, 97, 1-23,

4. Wang S. (2008) Environmental Science and Technology, 42, 7055-63,

5. Minjigmaa A., Zolzaya Ts., Davaabal B., Bayarzul U., Temuujin J. (2012) Mongolian Journal of Chemistry, 13(19), 78-81 